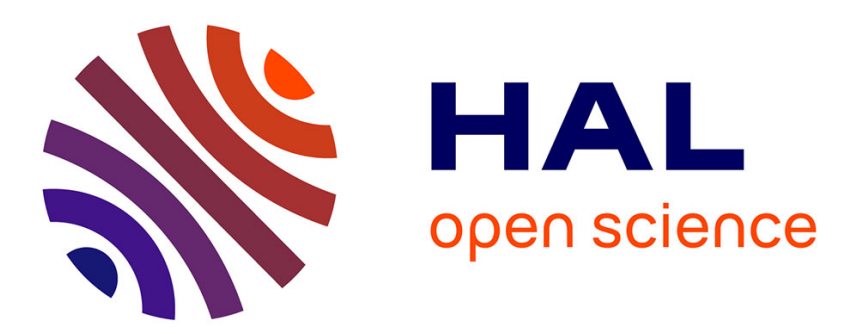

\title{
The Role of Noncovalent Interactions in the Efficiency of Dendrimers in Catalysis
}

\author{
Anne-Marie Caminade
}

\section{To cite this version:}

Anne-Marie Caminade. The Role of Noncovalent Interactions in the Efficiency of Dendrimers in Catalysis. Mahmudov, K. T.; Kopylovich, M. N.; Guedes da Silva, M. F. C.; Pombeiro, A. J. L. Catalysis Series, 36, RSC Publishing, pp.153-167, 2019, Noncovalent Interactions in Catalysis, 978-178801-468-7. 10.1039/9781788016490-00153 . hal-02360696

\section{HAL Id: hal-02360696 https://hal.science/hal-02360696}

Submitted on 4 Nov 2020

HAL is a multi-disciplinary open access archive for the deposit and dissemination of scientific research documents, whether they are published or not. The documents may come from teaching and research institutions in France or abroad, or from public or private research centers.
L'archive ouverte pluridisciplinaire HAL, est destinée au dépôt et à la diffusion de documents scientifiques de niveau recherche, publiés ou non, émanant des établissements d'enseignement et de recherche français ou étrangers, des laboratoires publics ou privés. 


\section{CHAPTER 7}

The role of noncovalent interactions on the efficiency of dendrimers in catalysis

Anne-Marie Caminade ${ }^{\mathrm{a}, \mathrm{b} *}$

${ }^{\text {a }}$ Laboratoire de Chimie de Coordination du CNRS, 205 Route de Narbonne, BP 44099, 31077 Toulouse Cedex 4, France.

${ }^{\mathrm{b}}$ LCC-CNRS, Université de Toulouse, CNRS, Toulouse, France

*Corresponding contributor. E-mail: anne-marie.caminade@1cc-toulouse.fr 


\section{Abstract}

Dendrimers are nanometric macromolecules constituted of repetitive branched units, radially arranged around a central core. They are synthesized step-by-step, generally using a divergent process from this core. Dendrimers have many properties, and among them, catalysis is a major field. Two main domains are studied, on one side the search for the positive "dendrimer effect", i.e. an increase of the catalytic efficiency when the size of the dendrimer increases, and on the other side the encapsulation of catalytically active nanoparticles inside dendrimers. In both cases, non-covalent interactions are involved.

This chapter displays the important role played by non-covalent interactions on the properties of dendrimers in catalysis. A first part will concern the dendrimer effect, then a short part will display non-covalently formed catalytic dendrimers, and the last part will concern dendrimers encapsulating catalytic nanoparticles. 


\subsection{Introduction}

Dendrimers are nanometric macromolecules constituted of repetitive branched units, radially arranged around a central core. The repetitive branched units can be considered as monomers, thus dendrimers pertain to the field of polymers, but contrarily to normal polymers, they are not synthesized by polymerization reactions, but step-by-step. In most cases, a divergent process is used, starting from a multifunctional core. Most processes necessitate two steps to build one generation, it means to obtain the same type of terminal functions, which number is multiplied by two or three at each generation (Figure 7.1). This multistep method of synthesis ensures both the homogeneity of each batch, and an excellent batch-tobatch reproducibility, contrarily to polymers. However, the synthesis of dendrimers is a lengthy and costly process, thus it appeared rapidly that it was needed to find some utility to these so aesthetic nano-objects. Three main fields have emerged in this context that are catalysis, materials, and biology/medicine. ${ }^{1}$

[Figure 7.1 near here]

Concerning the use of dendrimers for catalysis, the very first examples were published in 1994. Two examples concerned coordination complexes, on one side the electrochemical reduction of $\mathrm{CO}_{2}$ to $\mathrm{CO}$, using a small polyphosphine complexing palladium, ${ }^{2}$ and on the other side a Karash addition of polyhalogenoalkanes to carbon-carbon double bonds, using a small carbosilane dendrimer complexing nickel. $^{3}$ A third example concerned a polyether dendrimer having quaternary ammonium salts as terminal functions, which was used as efficient organocatalyst for the decarboxylation of 6-nitrobenzisoxazole-3carboxylate in water. ${ }^{4}$ After these pioneering works, two main areas gather most of the work carried out with catalytically active dendrimers. The first one concerns the search of the so-called "dendrimer (or dendritic) effect", 5 which is expected to be positive, it means an increase of the catalysis efficiency when the generation number of the dendrimer, and thus the density of terminal groups, increase. The second domain 
concerns catalytic metallic nanoparticles entrapped within dendrimers or covered by them. In both cases, non-covalent interactions are involved in the catalytic process. In addition, a few catalytically active dendrimers are synthesized by non-covalent, electrostatic interactions.

This chapter displays the important role played by non-covalent interactions when considering dendritic catalysts. It will display first the intriguing phenomenon that is the "dendrimer effect" in catalysis, followed by a short part about non-covalently formed dendritic catalysts. Finally, the last and largest part of this chapter will concern catalytically active nanoparticles interacting with dendrimers. In all cases, only pioneering examples, as well as selected recent examples will be given, as well as a number of reviews covering these fields.

\subsection{The dendrimer effect in catalysis}

The first examples of a dendritic effect in homogeneous catalysis concerned a family of carbosilane dendrimers from generation 0 to 2 , complexing nickel on each terminal function, and used for catalysing atom transfer radical additions, as the Karash addition of $\mathrm{CCl}_{4}$ to methylacrylate. A negative dendrimer effect was observed, as the most efficient catalyst was the monomer, and the least efficient the second generation dendrimer. This negative effect was ascribed to the proximity effect in which the catalytic sites interact more with the neighbouring catalytic site than with the reagents. ${ }^{8}$ The use of longer linkers on the surface, in order to increase the distance between the catalytic sites had indeed a positive influence on the efficiency, as the modified first generation was as active as the monomer ${ }^{9}$ (Figure 7.2).

[Figure 7.2 near here]

Negative dendrimer effects have been frequently observed, but we will display here essentially positive 
effects. Among the first examples one can cite in particular dendrimeric polyphenylselenides which catalyze the bromination of cyclohexene with hydrogen peroxide and $\mathrm{NaBr}$. Large increases in catalytic activity per phenylseleno group with each successive generation of the dendrimers were observed. Compared to the monomeric species, the reaction rate per terminal function was multiplied by 3 with generation zero, by 21 with generation one, and by 630 for generation two. ${ }^{10}$ It was proposed that autocatalysis is the source of this large dendrimer effect. ${ }^{11}$ Another example concerned PAMAM (polyamidoamine) dendrimers decorated with $\mathrm{Co}($ salen) complexes, applied to the hydrolytic kinetic resolution of terminal epoxides. The monomer had no activity, whereas the first generation dendrimer displayed $50 \%$ of reaction in $24 \mathrm{~h}$ (the theoretical maximum conversion), with an enantiomeric excess of $98 \%$. The positive dendritic effect was ascribed to cooperativity involving the simultaneous activation of both epoxide and nucleophile by two proximal salen units, a situation favored by the dendritic structure (Figure 7.3). ${ }^{12}$

[Figure 7.3 near here]

The influence of the internal structure of dendrimers on the catalytic properties has been proved by grafting Pyrphos ligands complexing palladium as terminal functions of PAMAM and PPI (polypropyleneimine) dendrimers, from the monomers to the third generations (Figure 7.4). Both families of complexes were tested for catalysing the allylic amination of 1,3-diphenyl-1-acetoxypropene with morpholine. The monomer displayed only $9 \%$ enantiomeric excess, whereas a remarkable increase in selectivity was observed as the generation of the dendrimer increased. The most efficient catalyst was the third generation PAMAM dendrimer ( $69 \%$ ee), to be compared with the third generation PPI dendrimer ( $40 \%$ ee). The positive influence of the increase of generations was ascribed to an increasingly crowded surface that may decrease the conformational flexibility of the terminal phenyl groups, but the difference induced by the internal structure was not explained. ${ }^{13}$ 
[Figure 7.4 near here]

Besides carbosilane, polyester, PAMAM and PPI dendrimers, phosphorhydrazone dendrimers also display an important role in catalysis. The first example of a positive dendritic effect concerned a series of phosphorhydrazone dendrimers decorated with ruthenium complexes of a diphosphine, for which the third generation (Figure 7.5a) was slightly more efficient than the first one and the monomer, for Knoevenagel condensations involving malonitrile and cyclohexanone. ${ }^{14}$ In another example, pyridine-imine terminal functions complexing $\mathrm{CuI}$ were used for coupling pyrazole with $\mathrm{PhI}$ or $\mathrm{PhBr}$. A clearly positive dendrimer effect was observed on going from the monomer to the dendrimers, from generations 1 to 3 (Figure $7.5 \mathrm{~b}$ ). ${ }^{15}$ Generations 1 to 3 of phosphorhydrazone dendrimers bearing as terminal functions water-soluble phosphatriazaadamantane ligands complexing ruthenium were used as catalysts in aqueous media (Figure 7.5c). A largely positive effect was observed in the rate and yield of the catalysed isomerisation of allylic alcohols to ketones. ${ }^{16}$ Terminal phosphoramidite ligands complexing rhodium have been found highly effective in terms of activity and enantiodiscrimination for catalysed $[2+2+2]$ cycloaddition reactions, for all generations from 1 to 3 , compared to the monomer (Figure $7.5 \mathrm{~d}) .{ }^{17}$

[Figure 7.5 near here]

Most of the previous examples concern organometallic catalysis, using metal complexes as terminal groups of dendrimers. However, organocatalysis was also carried out with some dendrimers, in particular when using peptide dendrimers. These dendrimers were assayed for catalysing the hydrolysis of esters. It was first shown that histidine residues on the surface were the most active for this reaction. ${ }^{18}$ Histidine-serine units used not only as terminal functions but also in the internal structure afforded a series of peptide dendrimers which displayed a strong positive dendrimer effect. The specific reactivity enhancement per catalytic site was 44 for the first generation, and 4500 for the fourth generation (Figure 7.6a). ${ }^{19}$ In another example of 
organocatalysis, several generations of folded prolinamide dendrons based on pyridine-2,6-dicarboxamide branching units were used for catalysing aldol reactions (Figure 7.6b). Positive dendritic effects were observed on both the enantioselectivity and the diastereoselectivity. ${ }^{20}$

[Figure 7.6 near here]

\subsection{Non-covalently formed dendritic catalysts}

Supramolecular dendrimers are constituted by the non-covalent assembly of branches with a scaffold. ${ }^{21} \mathrm{~A}$ few of them have catalytic properties. In these cases, the non-covalent interaction concerns the structure of the dendrimer, but can involve the catalytic sites also. Poly(propylene imine) dendrimers functionalized with urea adamantyl terminal functions were used as supports for phosphine ligands equipped with urea acetic groups (Figure 7.7a). The resulting supramolecular complex has been used in the palladium-catalysed allylic amination reaction of crotyl acetate and piperidine, both in a batch process and in a continuous flow membrane reactor. $^{22}$

An octacationic core derived from tetraphenylsilane and functionalized with arylether dendrons was used to interact with a sulfato monoanionic pincer ligand complexing palladium (Figure 7.7b). This assembly was used as Lewis acid catalyst in the aldol condensation of benzaldehyde and methyl isocyanatoacetate. ${ }^{23}$ The same family of supramolecular dendrimers was expanded later up to generation 3, for catalysing the same reaction, but a slightly detrimental effect on the catalytic efficiency was observed when increasing the generation number. $^{24}$

Host-guest systems based on vitamin $\mathrm{B}_{2}$ derivative and dendritic 2,5-bis(acylamino) pyridine (Figure 7.7c) were used as organocatalyst for the aerobic reduction of olefins with 1 equiv. of hydrazine under an 
atmosphere of $\mathrm{O}_{2}$ or air. Two different types of branches were used for constituting the dendrimer. Aryl ether branches were synthesized up to the third generation. A remarkable enhancement of catalytic activity was observed in the reduction of aromatic and/or hydroxyl olefins. ${ }^{25}$ 3,4,5-trialkoxyphenyl groups as terminal functions were applied in the same reaction, with the same efficiency. ${ }^{26}$ In these cases, the noncovalent interaction concerns the catalytic site.

The reaction of three dendrons having an ammonium at the core with the heteropolyacid $\mathrm{H}_{3} \mathrm{PW}_{12} \mathrm{O}_{40}(\mathrm{POM})$ in the presence of hydrogen peroxide afforded by ionic interactions air stable catalysts. In this case also, the non-covalent interaction concerns the catalytic site (Figure 7.7d). These compounds were used as recoverable catalysts for the selective oxidation of alkenes to epoxides, of sulfides to sulfones, and of alcohols to ketones, in an aqueous/ $\mathrm{CDCl}_{3}$ biphasic system. The dendritic structure increased the stability of the POM species and facilitated the recovery of the catalyst up to the eighth cycle. The reaction kinetics were susceptible to the nature of the peripheral end groups; the $n$-propyl-terminated dendron afforded the most active catalyst. ${ }^{27}$

In a last example of non-covalent interactions, a small phosphorhydrazone dendrimer having a pyrene group linked to the core and phosphines for the complexation of palladium as terminal functions was used first for interacting by $\pi$-stacking with the graphene layers covering magnetic cobalt nanoparticles (Figure 7.7e). This assembly was used for catalysing the Suzuki couplings of $\mathrm{ArBr}$ and $\mathrm{PhB}(\mathrm{OH})_{2}$, in particular for the synthesis of Felbinac (an anti-inflammatory drug). The reaction occurred by heating to $60^{\circ} \mathrm{C}$; at this temperature, the dendrimer is in solution to perform the catalysis, and not on the surface of the Conanoparticle. At the end of the reaction, the dendrimers went back onto the Co-nanoparticles, and the assembly could be recovered to be re-used in a next catalytic experiment. The recovery and re-use was very efficient, as the process could be applied 12 times, without any decrease in the catalytic efficiency. ${ }^{28}$ 
[Figure 7.7 near here]

\subsection{Dendrimer-encapsulated nanoparticles as catalysts}

Metal nanoparticles are known catalysts since a long time, and the nature of the stabilizer is particularly important for the efficiency of the catalysis. Thus dendrimers have been used for both controlling the size of the nanoparticles and preventing their agglomeration. In addition, the dendrimer is a weak adsorbent for the nanoparticles, and can act as a nanofilter, that permit the passage of the substrates and products. Depending on the size of the dendrimer, i.e. its generation, and the size of the nanoparticle, either the nanoparticles are inside the dendrimer, for high generations, or a nanoparticle is surrounded by several dendrimers, for low generations.

In most cases, the dendrimers used for the encapsulation of the nanoparticles are of type PAMAM. The very first examples of dendrimers used for such purpose were proposed by R.M. Crooks, using hydroxylterminated PAMAM dendrimers (Figure 7.8a) of generations 4, 6, and 8, for encapsulating Pd and $\mathrm{Pt}$ nanoparticles. These nanoparticles were used for catalysing the hydrogenation of alkenes. ${ }^{29}$ The role of nanofilter played by the dendrimer was emphasized when using branched olefins, for which the turnover frequency (TOF) of the hydrogenation was decreased compared to that of linear olefins. ${ }^{30}$ The same assembly of PAMAM-OH dendrimers with $\mathrm{Pt}$ nanoparticles confined to electrode surfaces act as electrocatalysts for $\mathrm{O}_{2}$ reduction. ${ }^{31}$ Two reviews have emphasized the first works in the field. ${ }^{32,33}$

More recent results from the same group concern the electrocatalytic oxidation of formic acid with PAMAM-encapsulated nanoparticles, either of $\mathrm{Pt},{ }^{34}$ or of type core shell $\mathrm{Au} / \mathrm{Pt}^{35}$ In the case of $\mathrm{Au}$ nanoparticles used for the electrocatalytic reduction of $\mathrm{CO}_{2}$, it was shown that the size of the nanoparticles encapsulated in small dendrimers grows rapidly during the electrocatalysis, whereas the size of those 
encapsulated in high generations dendrimers (G8) does not change. ${ }^{36}$ Another recent experiment concerned the comparison between the efficiency of PtAu and PdAu random nanoparticles encapsulated in PAMAM dendrimers used for the hydrogenation of allylic alcohol. It was shown that the efficiency of PtAu nanoparticles increased linearly when the Pt content increased, whereas the most efficient PdAu nanoparticles were those composed of $60 \%$ of $\mathrm{Pd} .{ }^{37}$

Other groups have used also PAMAM dendrimers for the encapsulation of metallic nanoparticles. Silver, palladium and platinum nanoparticles encapsulated in PAMAM but also in PPI dendrimers have been used for the reduction of 4-nitrophenol. The rate constants for the PPI dendrimers encapsulating Pt and Pd nanoparticles were significantly greater than those for the PAMAM dendrimers encapsulating the same nanoparticles. ${ }^{38}$ The same type of experiments was carried out with gold nanoparticles, and using a dialysis membrane bag for recycling the catalyst. ${ }^{39}$ PAMAM dendrimers (G3 to G5) encapsulating Pd nanoparticles were covalently anchored to glass micro-reactors. They were used for Suzuki-Miyaura cross-coupling catalysis, and exhibited excellent reactivity compared to other Pd nanoparticles flow reactors. This assembly exhibited good stability, with a Pd leaching of only $1.2 \mathrm{ppm}$ after more than 7 days of reaction. ${ }^{40}$

PAMAM G4-OH dendrimers encapsulating rhodium nanoparticles and supported on mesoporous silica were used for catalysing the ring opening of cyclopropylbenzene under hydrogen. The linear products were formed with $100 \%$ selectivity. ${ }^{41}$ Additional work with Pd, Pt and Rh nanoparticles and PAMAM dendrimers supported on silica afforded efficient catalysts for the acceptorless dehydrogenation of tetrahydroquinoline/indoline derivatives. Moreover, the encapsulated Pd nanoparticles were used for catalysing the direct arylation of indole in water, with hypervalent iodine as oxidant, demonstrating the potential of this system to catalyse tandem processes. ${ }^{42}$ The same process was applied to gold nanoparticles covered by $\mathrm{N}$-heterocyclic carbenes (NHC), which enabled a lactonization reaction to proceed at $20^{\circ} \mathrm{C}$ instead of over $80^{\circ} \mathrm{C}$ for the "naked" (without $\mathrm{NHC}$ ) nanoparticles. ${ }^{43}$ PAMAM dendrimers having a 
cystamine cleavable core (Figure 7.8b) were used for the functionalization of single-walled carbon nanotubes, followed by the formation and encapsulation of Pd nanoparticles. These functional nanomaterials were found efficient catalysts in Suzuki and Heck reactions, with a turnover number (TON) of 48,000 and a turnover frequency (TOF) of 5666,000 $\mathrm{h}^{-1}$. The catalyst could be recovered and reused for up to 6 times, and no leaching of metal was detected. ${ }^{44} \mathrm{~A}$ review has emphasized the properties of supported dendrimersencapsulated nanoparticles. $^{45}$

[Figure 7.8 near here]

Other types of dendrimers have been proposed for encapsulation of nanoparticles used as catalysts. The quantity of metal used can be very small, even "homeopathic": with 1 ppm of Pd nanoparticles stabilized by a carbosilane ferrocenyl dendrimer containing triazole units of generation zero (Figure 7.9a), the product of the Suzuki coupling of $\mathrm{PhI}$ with $\mathrm{PhB}(\mathrm{OH})_{2}$ was obtained in $54 \%$ yield, and the TON (turn over number) was $540,000 .^{46}$ The first generation of the same series (Figure $7.9 \mathrm{~b}$ ) encapsulating also Pd nanoparticles is a highly efficient and size-selective hydrogenation catalyst for a series of different olefines. ${ }^{47}$ Another member of the same series of dendrimers, having PEG (polyethyleneglycol) terminal functions (Figure 7.9c) was used for the stabilization of $\mathrm{Au}, \mathrm{Ag}$ and $\mathrm{Cu}$ nanoparticles. The $\mathrm{Au}$ NPs were used for catalyzing the reduction of 4-nitrophenol, whereas the $\mathrm{Cu}$ NPs were used as catalyst for the alkyne azide cycloaddition. ${ }^{48}$ Two reviews gave accounts of this work with Pd nanoparticles. ${ }^{49,50}$

[Figure 7.9 near here]

Phosphorhydrazone dendrimers and dendrons diversely functionalized have been used also for stabilizing nanoparticles. In the first case, dendrimers bearing triazatriolefinic macrocycles as terminal functions of generations 0,1 and 4 (Figure 7.10a) were able to generate and stabilize palladium nanoparticles. These 
nanoparticles were used for catalysing the Mizoroki-Heck reaction between iodobenzene and nbutylacrylate. The catalysts were recovered and reused five times and displayed an increasing activity, correlated with a decrease of the size of the nanoparticles. ${ }^{51}$ Phosphorhydrazone dendrons (generation 0 to 2) having an alkyl chain at the focal point and triarylphosphines on the surface (Figure 7.10b) were used for preparing and stabilizing ruthenium nanoparticles. They were used as catalysts for the hydrogenation of styrene. The systems involving second-generation dendrons displayed higher catalytic activity compared to those involving smaller dendrons. ${ }^{52}$

Phenylazomethine dendrimers of generation 4 (Figure 7.10c) were used for preparing rhodium nanoparticles, and bimetallic $\mathrm{Rh} / \mathrm{Fe}$ nanoparticles. They were tested for the reduction of olefinic substrates under a hydrogen atmosphere (1 atm). The $\mathrm{Rh} / \mathrm{Fe}$ nanoparticles showed enhanced catalytic activity over the Rh nanoparticles. Hydrogenation of nitroarenes for obtaining aniline derivatives were carried out, and in this case too, bimetallic catalysts were more efficient (up to 8.5-times) than the Rh nanoparticle catalysts. ${ }^{53} \mathrm{~A}$ recent review has emphasised the catalytic efficiency of bimetallic nanoparticles encapsulated by dendrimers. ${ }^{54}$ The same dendrimers were used for stabilizing two platinum clusters, $\mathrm{Pt}_{13}$ and $\mathrm{Pt}_{12}$. The catalytic activity for oxygen reduction reaction using these clusters significantly increased for $\mathrm{Pt}_{12}$ compared to $\mathrm{Pt}_{13}{ }^{55}$

[Figure 7.10 near here]

\subsection{Conclusion}

The role of non-covalent interaction for catalyses carried out with dendrimers present different facets that have been highlighted in this chapter. The first one concerns a positive dendrimer effect that is an increase of the catalytic efficiency when the generation of the dendrimer increases. This effect is generally attributed to 
the closer proximity of the catalytic entities on the surface of the dendrimers, which may facilitate the catalysis. However, this close proximity can be also detrimental for the outcome of the catalysis; a negative dendrimer effect is observed in these cases. Non-covalent interactions, in most cases ionic interactions, have been used also for the synthesis of some catalytically active dendrimers. Finally, different types of catalytically active metallic of bimetallic nanoparticles have been encapsulated within large dendrimers, or covered by small dendrimers through non-covalent interactions in both cases. Furthermore, the dendrimer can act as a nanofilter that can select the substrates (in particular linear versus branched).

Despite a relatively long time since the pioneering works (1994), a lot of work has still to be done concerning catalysis with dendrimers. The origin of the positive dendrimer effect, which is believed to be due to non-covalent interactions between terminal functions in close proximity, in not fully understood. Concerning the encapsulation of metallic nanoparticles, some recent papers have emphasized that subtle changes can totally modify the catalytic properties. The precise location of the nanoparticles, ${ }^{48}$ and the precise number of atoms constituting the nanoparticles ${ }^{55}$ appears as particularly important for rationalizing the catalytic efficiency of these assemblies in the future.

\section{Acknowledgement}

Thanks are due to the CNRS for financial support.

\section{References*}

1. Dendrimers. Towards Catalytic, Material and Biomedical Uses. Caminade A.M., Turrin C.O., Laurent R., Ouali A., Delavaux-Nicot B., Eds., John Wiley \& Sons, Chichester (UK), 2011.

2. A. Miedaner, C.J. Curtis, R.M. Barkley and D.L. DuBois, Inorg. Chem., 1994, 33, 5482. 
3. J.W.J. Knapen, A.W. van der Made, J.C. de Wilde, P. van Leeuwen, P. Wijkens, D.M. Grove and G. van Koten, Nature, 1994, 372, 659.

4. J.J. Lee, W.T. Ford, J. A. Moore and Y. Li, Macromolecules, 1994, 27, 4632.

5. B. Helms and J.M.J. Frechet, Adv. Synth. Catal., 2006, 348, 1125.

6. R.S. Bagul and N. Jayaraman, Inorg. Chim. Acta, 2014, 409, 34.

7. A.M. Caminade, A. Ouali, R. Laurent, C.O. Turrin and J.P. Majoral, Chem. Soc. Rev., 2015, 44, 3890.

8. A.W. Kleij, R.A. Gossage, J. Jastrzebski, J. Boersma and G. van Koten, Angew. Chem. Int. Ed., 2000, 39, 176.

9. A.W. Kleij, R.A. Gossage, R. Gebbink, N. Brinkmann, E.J. Reijerse, U. Kragl, M. Lutz, A.L. Spek and G. van Koten, J. Am. Chem. Soc., 2000, 122, 12112.

10. C. Francavilla, F.V. Bright and M.R. Detty, Org. Lett., 1999, 1, 1043.

11. M. D. Drake, F.V. Bright and M.R. Detty, J. Am. Chem. Soc., 2003, 125, 12558.

12. R. Breinbauer and E.N. Jacobsen, Angew. Chem. Int. Ed., 2000, 39, 3604.

13. Y. Ribourdouille, G.D. Engel, M. Richard-Plouet and L.H. Gade, Chem. Commun., 2003, 1228.

14. V. Maraval, R. Laurent, A.M. Caminade and J.P. Majoral, Organomet., 2000, 19, 4025.

15. A. Ouali, R. Laurent, A.M. Caminade, J.P. Majoral J.P. and M. Taillefer, J. Am. Chem. Soc., 2006, 128, 15990.

16. P. Servin, R. Laurent, L. Gonsalvi, M. Tristany, M. Peruzzini, J.P. Majoral and A.M. Caminade, Dalton Trans., 2009, 4432.

17. L. Garcia, A. Roglans, R. Laurent, J. P. Majoral, A. Pla-Quintana and A. M. Caminade, Chem. Commun., 2012, 48, 9248 .

18. A. Esposito, E. Delort, D. Lagnoux, F. Djojo and J.L. Reymond, Angew. Chem. Int. Ed., 2003, 42, 1381.

19. E. Delort, T. Darbre and J.L. Reymond, J. Amer. Chem. Soc., 2004, 126, 15642.

20. K. Mitsui, S. A. Hyatt, D. A. Turner, C. M. Hadad and J. R. Parquette, Chem. Commun., 2009, 3261.

21. R. Dong, Y. Zhou and X. Zhu, Acc. Chem. Res., 2014, 47, 2006. 
22. D. de Groot, B.F.M. de Waal, J.N.H. Reek, A. Schenning, P.C.J. Kramer, E.W. Meijer and P. van Leeuwen, J. Am. Chem. Soc., 2001, 123, 8453.

23. R. van de Coevering, M. Kuil, R. Gebbink and G. van Koten, Chem. Commun., 2002, 1636.

24. R. van de Coevering, A.P. Alfers, J.D. Meeldijk, E. Martinez-Viviente, P.S. Pregosin, R.J.M.K. Gebbink and G. van Koten, J. Am. Chem. Soc., 2006, 128, 12700.

25. Y. Imada, H. Iida, T. Kitagawa and T. Naota, Chem.-Eur. J., 2011, 17, 5908.

26. Y. Imada, Y. Kugimiya, S. Iwata, N. Komiya and T. Naota, Tetrahedron, 2013, 69, 8572.

27. S. Nlate, L. Plault and D. Astruc, Chem.-Eur. J., 2006, 12, 903.

28. M. Keller, V. Colliere, O. Reiser, A.M. Caminade, J.P. Majoral and A. Ouali, Angew. Chem. Int. Ed., $2013, \mathbf{5 2}, 3626$.

29. M. Q. Zhao and R. M. Crooks, Angew. Chem. Int. Ed., 1999, 38, 364.

30. Y. H. Niu, L. K. Yeung and R. M. Crooks, J. Am. Chem. Soc., 2001, 123, 6840.

31. M. Q. Zhao and R. M. Crooks, Adv. Mater., 1999, 11, 217.

32. R. M. Crooks, M. Q. Zhao, L. Sun, V. Chechik and L. K. Yeung, Acc. Chem. Res., 2001, 34, 181.

33. R. W. J. Scott, O. M. Wilson and R. M. Crooks, J. Phys. Chem. B, 2005, 109, 692.

34. N. Ostojic, J. H. Thorpe and R. M. Crooks, J. Am. Chem. Soc., 2016, 138, 6829.

35. R. Iyyamperumal, L. Zhang, G. Henkelman and R. M. Crooks, J. Am. Chem. Soc., 2013, 135, 5521.

36. J. A. Trindell, J. Clausmeyer and R. M. Crooks, J. Am. Chem. Soc., 2017, 139, 16161.

37. L. Luo, Z. Y. Duan, H. Li, J. Kim, G. Henkelman and R. M. Crooks, J. Am. Chem. Soc., 2017, 139, 5538.

38. K. Esumi, R. Isono and T. Yoshimura, Langmuir, 2004, 20, 237.

39. M. Nemanashi and R. Meijboom, Catal. Commun., 2016, 83, 53.

40. R. Ricciardi, J. Huskens, M. Holtkamp, U. Karst and W. Verboom, ChemCatchem, 2015, 7, 936.

41. R. Ye, B. Yuan, J. Zhao, W.T. Ralston, C.-Y. Wu, E.U. Barin, F.D. Toste and G.A. Somorjai, J. Am. Chem. Soc., 2016, 138, 8533.

42. C.V. Deraedt, R. Ye, W. Ralston, F.D. Toste and G.A. Somorjai, J. Am. Chem. Soc., 2017, 139, 18084. 
43. R. Ye, A.V. Zhukhovitskiy, R.V. Kazantsev, S.C. Fakra, B.B. Wickemeyer, F.D. Toste and G.A. Somorjai, J. Am. Chem. Soc., 2018, 140, 4144.

44. F. Giacalone, V. Campisciano, C. Calabrese, V. La Parola, Z. Syrgiannis, M. Prato and M. Gruttadauria, ACS Nano, 2016, 10, 4627.

45. R. Ye, A.V. Zhukhovitskiy, C.V. Deraedt, F.D. Toste and G.A. Somorjai, Acc. Chem. Res., 2017, 50, 1894.

46. A.K. Diallo, C. Ornelas, L. Salmon, J.R. Aranzaes and D. Astruc, Angew. Chem. Int. Ed., 2007, 46, 8644.

47. C. Ornelas, J.R. Aranzaes, L. Salmon and D. Astruc, Chem.-Eur. J., 2008, 14, 50.

48. X. Liu, D. Gregurec, J. Irigoyen, A. Martinez, S. Moya, R. Ciganda, P. Hermange, J. Ruiz and D. Astruc, Nature Communications, 2016, 7:13152.

49. D. Astruc, C. Ornelas, A.K. Diallo and J. Ruiz, Molecules, 2010, 15, 4947.

50. C. Deraedt and D. Astruc, Acc. Chem. Res., 2014, 47, 494.

51. E. Badetti, A.M. Caminade, J.P. Majoral, M. Moreno-Manas and R. M. Sebastian, Langmuir, 2008, 24, 2090.

52. N.G. Garcia-Pena, A.M. Caminade, A. Ouali, R. Redon and C.O. Turrin, RSC Adv., 2016, 6, 64557.

53. I. Nakamula, Y. Yamanoi, T. Imaoka, K. Yamamoto and H. Nishihara, Angew. Chem. Int. Ed., 2011, 50, 5830.

54. H. Wang and G.L. Rempel, Polymer Reviews, 2016, 56, 486.

55. T. Imaoka, H. Kitazawa, W.J. Chun, S. Omura, K. Albrecht and K. Yamamoto, J. Am. Chem. Soc., 2013, 135, 13089. 


\section{Figure Captions}

Figure 7.1 Schematized step-by-step synthesis of dendrimers.

Figure 7.2 First generations of carbosilane dendrimers having a short or long linker between the dendrimer and the catalytic entities. The second one is a more active catalyst for the Karash addition of $\mathrm{CCl}_{4}$ to methylacrylate.

Figure 7.3 a) Dendrimeric polyphenylselenides suitable for catalyzing the bromination of cyclohexene; b) PAMAM dendrimers decorated with salen complexes used for catalyzing the hydrolytic kinetic resolution of terminal epoxides; both families of catalysts display positive dendrimer effect.

Figure 7.4 PAMAM and PPI dendrimers of generation 4, decorated with the same type of catalytic entities, and used in the allylic amination of 1,3-diphenyl-1-acetoxypropene with morpholine.

Figure 7.5 Diverse types of phosphorhydrazone dendrimers catalysts displaying positive dendritic effects; a) for Knoevenagel condensations involving malonitrile and cyclohexanone; b) for coupling pyrazole with $\mathrm{PhI}$ or $\mathrm{PhBr}$; c) for the catalysed isomerisation of allylic alcohols to ketones in aqueous media; d) for catalysed $[2+2+2]$ cycloaddition reactions.

Figure 7.6 Two examples of dendrimers used as organocatalysts; a) peptide dendrimer for catalysing the hydrolysis of esters; b) pyridine-2,6-dicarboxamide dendron with prolinamide terminal groups used as catalyst for aldol reactions.

Figure 7.7 Non-covalent interactions for the synthesis of catalytic dendrimers (a to d), and for the recovery 
of the dendritic catalyst (e). a) for palladium-catalysed allylic aminations; b) as Lewis acid catalysts for the aldol condensation of benzaldehyde and methyl isocyanatoacetate; c) for the aerobic reduction of aromatic and/or hydroxyl olefins; d) as recoverable catalysts for the selective oxidation of alkenes to epoxides, of sulphides to sulfones, and of alcohols to ketones; e) for catalysing the coupling of $\mathrm{ArBr}$ and $\mathrm{PhB}(\mathrm{OH})_{2}$.

Figure 7.8 Two types of PAMAM dendrimers used for encapsulating diverse types of nanoparticles. a) for $\mathrm{Pd}, \mathrm{Pt}, \mathrm{Rh}, \mathrm{Au}, \mathrm{Ag}$, and bimetallic $\mathrm{Au} / \mathrm{Pt}$ and $\mathrm{Au} / \mathrm{Pd}$ nanoparticles; b) for the functionalization of singlewalled carbon nanotubes and the encapsulation of Pd nanoparticles, then used for Suzuki and Heck reactions.

Figure 7.9 Three examples of triazole dendrimers for the stabilization of palladium nanoparticles. a) for Suzuki couplings; b) for hydrogenation of olefins; c) Au nanoparticles for the reduction of 4-nitrophenol, and $\mathrm{Cu}$ nanoparticles for alkyne azide cycloadditions.

Figure 7.10 Diverse types of dendrimers encapsulating nanoparticles. a) phosphorhydrazone dendrimer with macrocycle as terminal functions for catalysing Mizoroki-Heck reactions of iodobenzene and nbutylacrylate; b) phosphorhydrazone dendron with phosphine terminal functions for the complexation of Ru nanoparticles used for the hydrogenation of styrene; c) phenylazomethine dendrimer for $\mathrm{Rh}$ and $\mathrm{Rh} / \mathrm{Fe}$ hydrogenation of nitroarene. 
THE FOLLOWING IMAGES SHOULD BE SUPPLIED AS SEPARATE FILES in one of the following formats: TIFF/PDF/EPS/DOC/XLS/PPT/JPEG/CDX

Figure 7.1

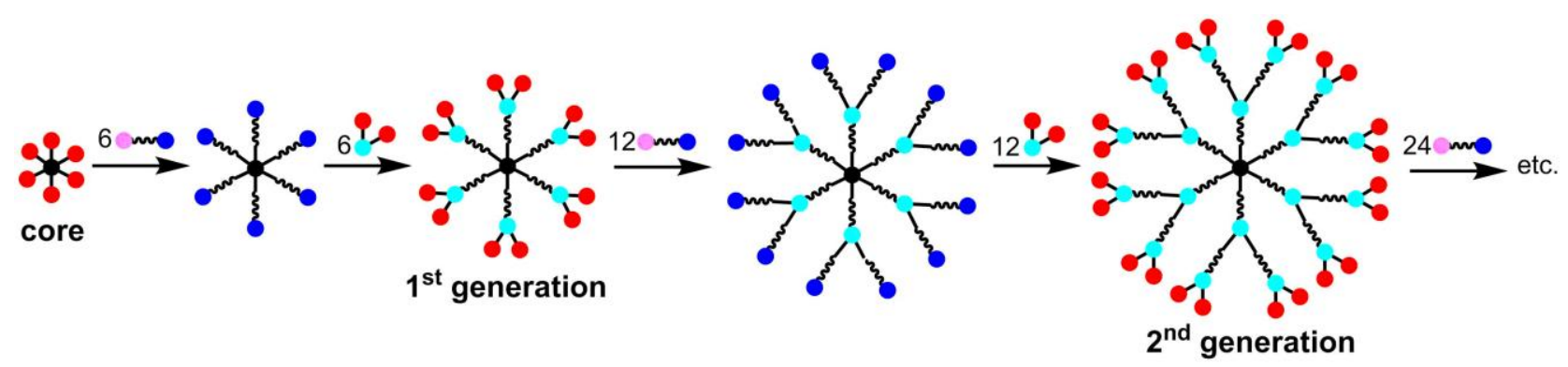


Figure 7.2
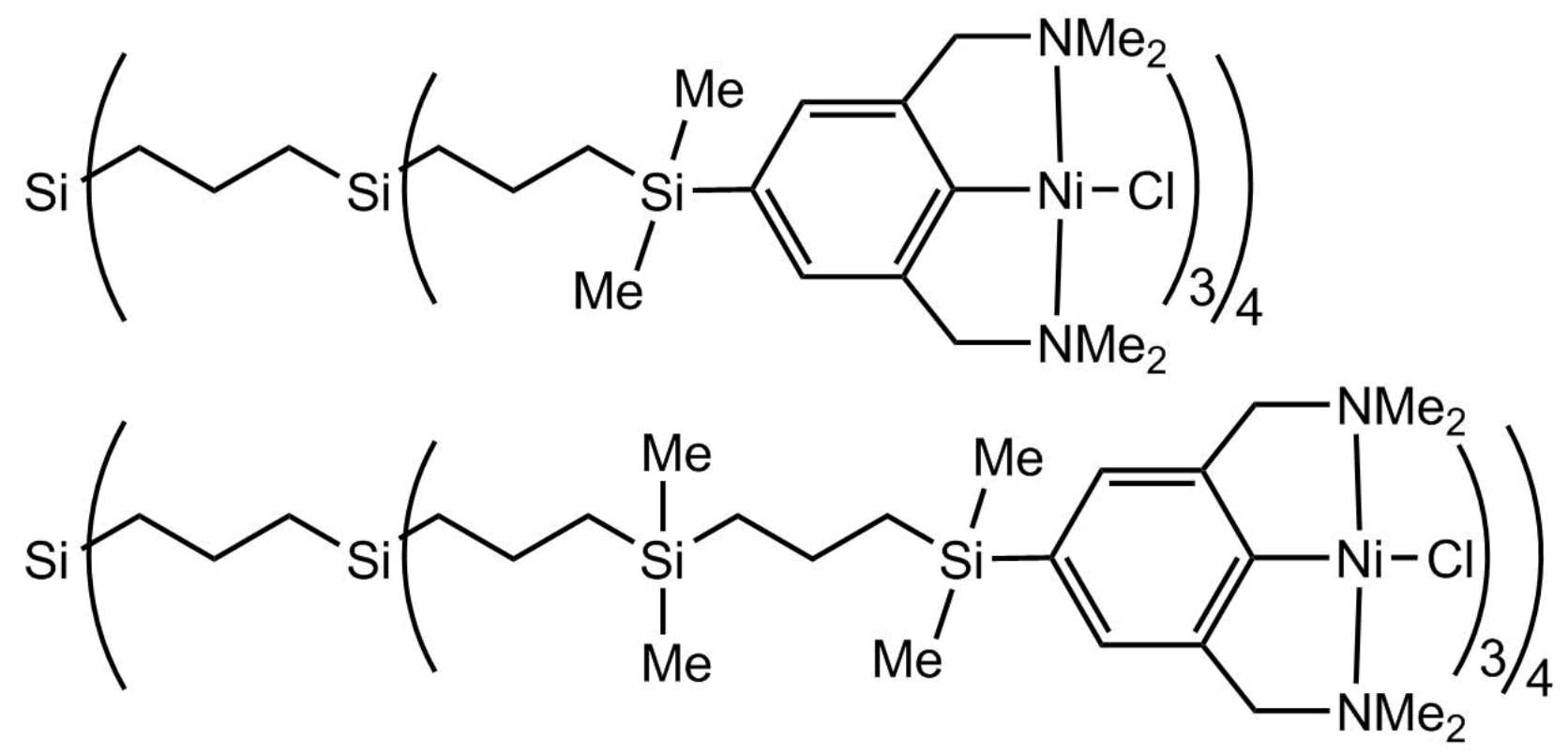
Figure 7.3

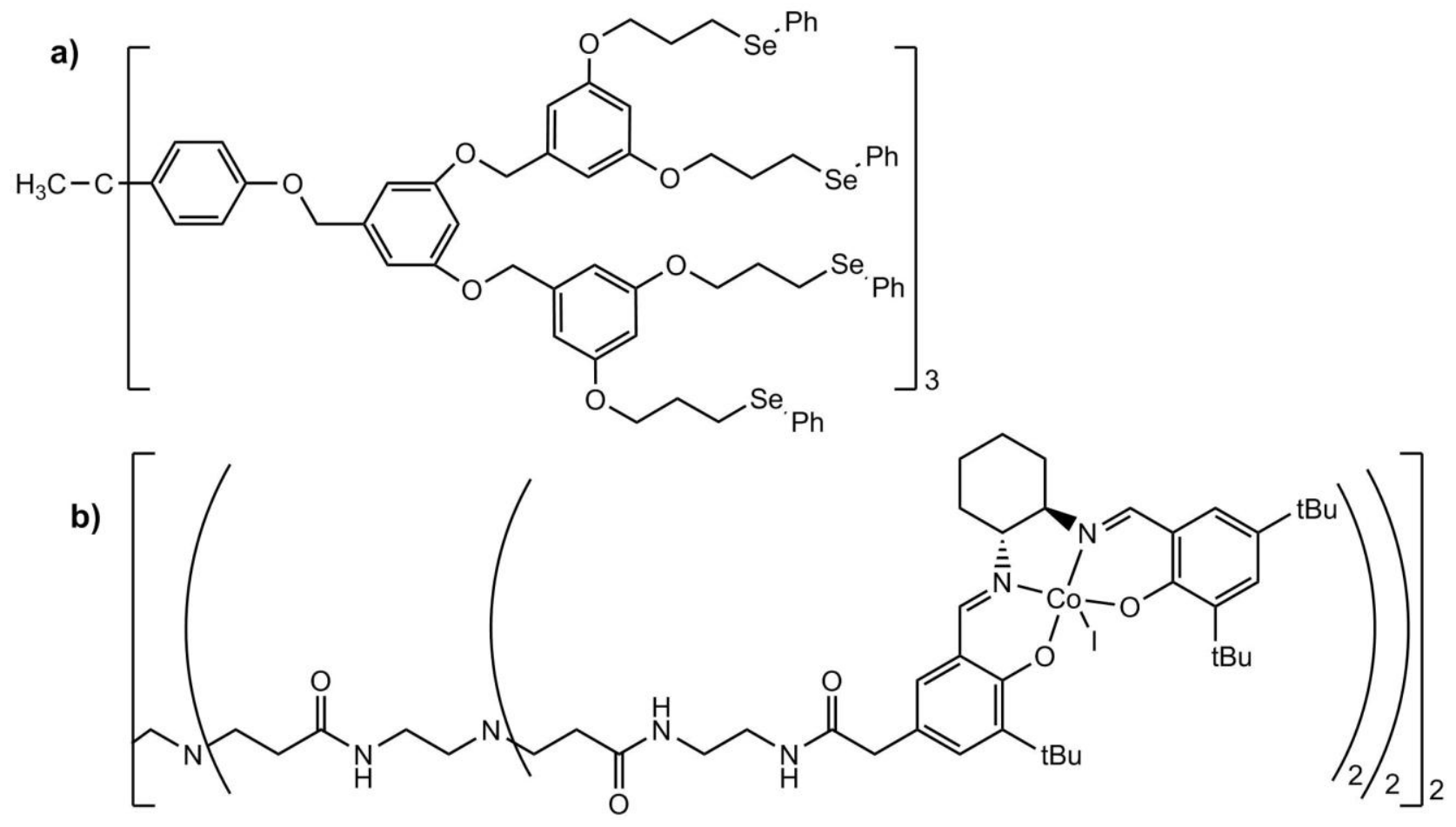


Figure 7.4

(N) 


\section{Figure 7.5}

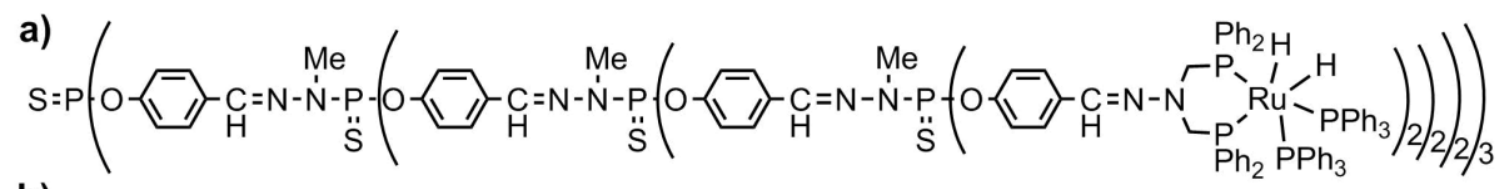

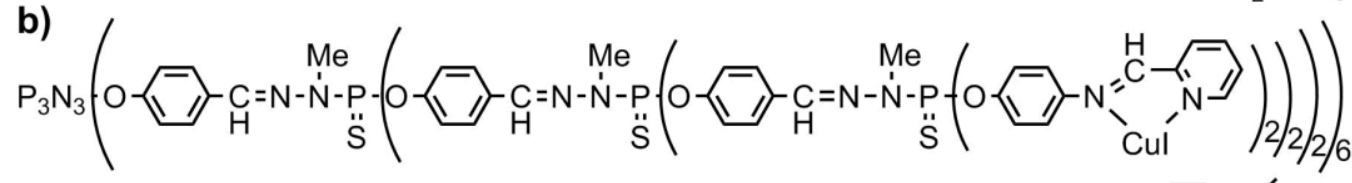

c)

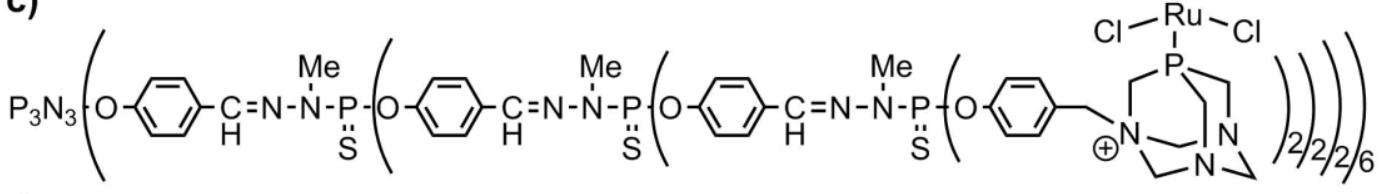

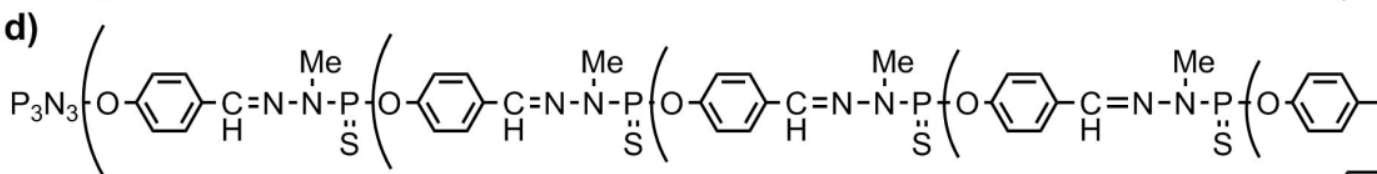

$\left(\mathrm{C}_{2} \mathrm{H}_{4}\right)_{2} \mathrm{RhCl}$ 
Figure 7.6

a)

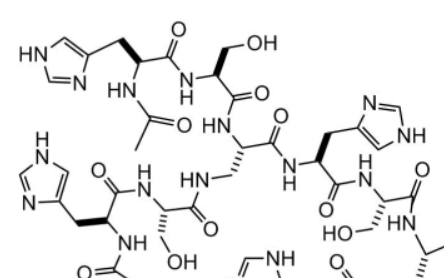<smiles>O=C1CC(=O)N[C@@H](Cc2c[nH]cn2)C1</smiles><smiles>CNC(=O)[C@H](CNC(=O)[C@H](CO)NC(=O)[C@H](CO)NC(C)=O)NC(=O)[C@H](CO)NC(=O)[C@H](Cc1cn[nH]c1)NC(C)=O</smiles><smiles>CNC(=O)[C@H](Cc1c[nH][nH]1)NC=O</smiles>
(n)

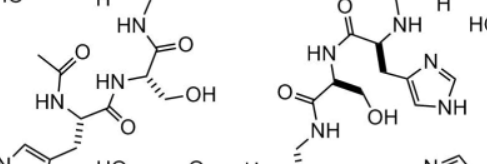

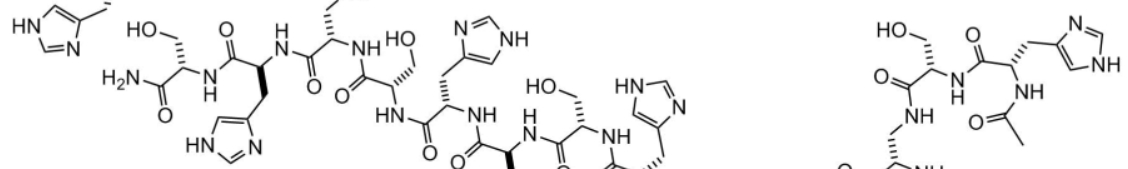
(n)

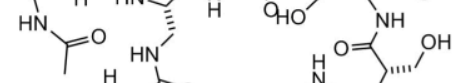
OH (n)

b)

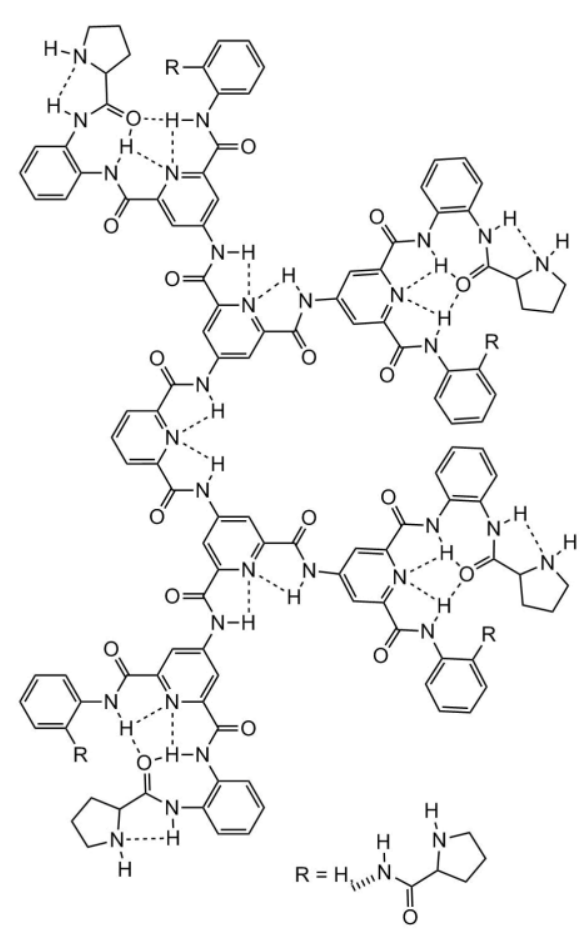




\section{Figure 7.7}

a)

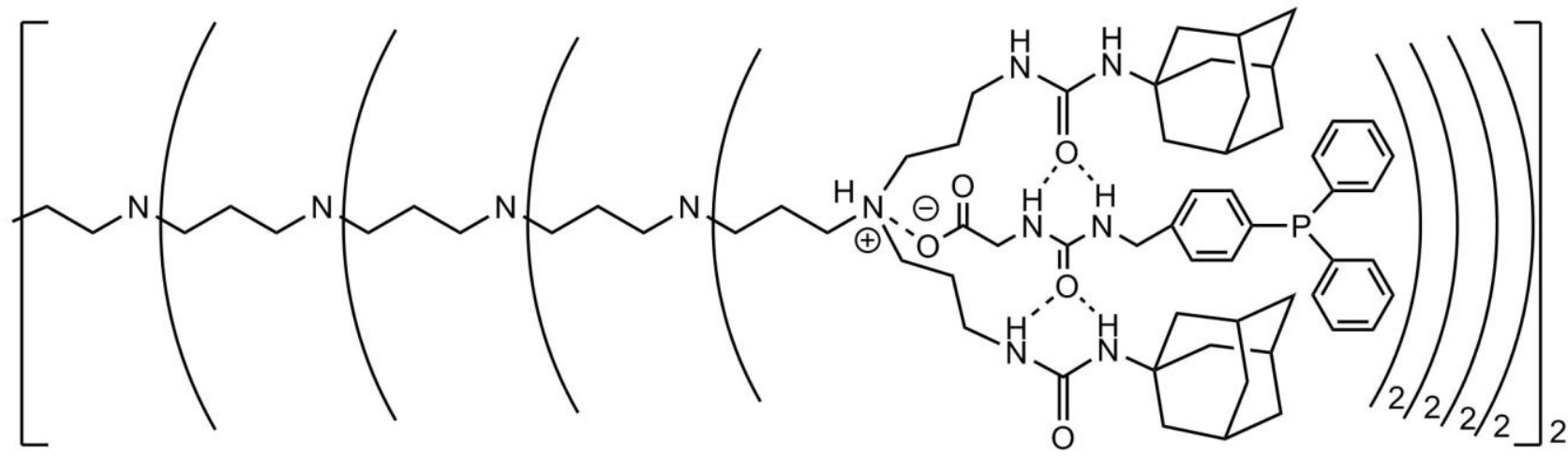

b)

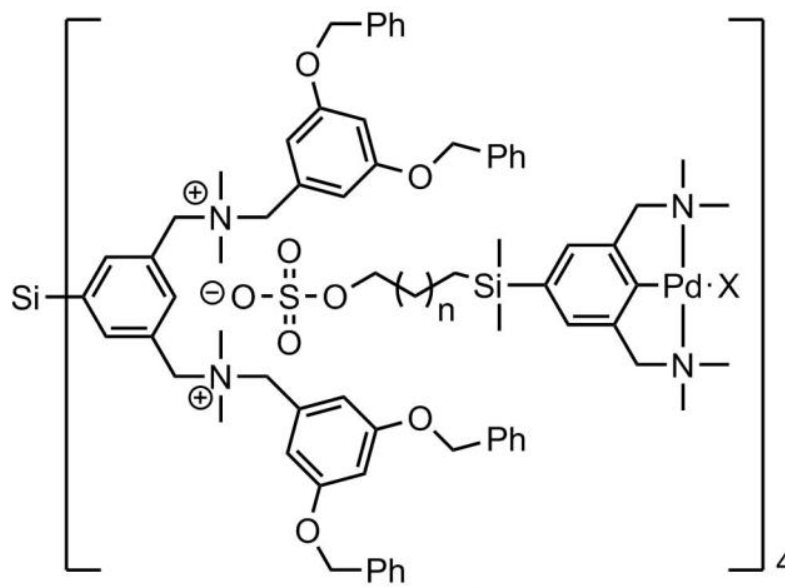

$\mathrm{n}=1,4$

$\mathrm{X}=\mathrm{Cl}, \mathrm{OH}_{2} \mathrm{BF}_{4}$

c)<smiles></smiles>

d)

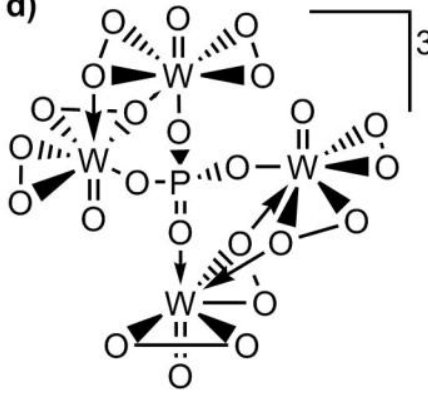

e)

(-

graphene layer on the surface of Co nanoparticle 
Figure 7.8

a)

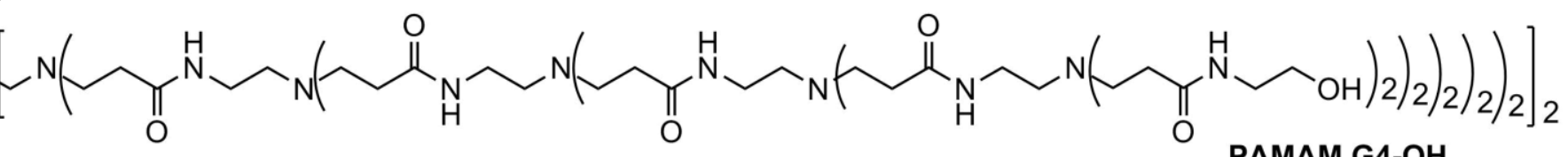

b)<smiles>CN(CCN)CCNC(=O)CCN(C)CCN(C)CCNC(=O)CCN(C)CCSC(C)(C)C</smiles> 
Figure 7.9

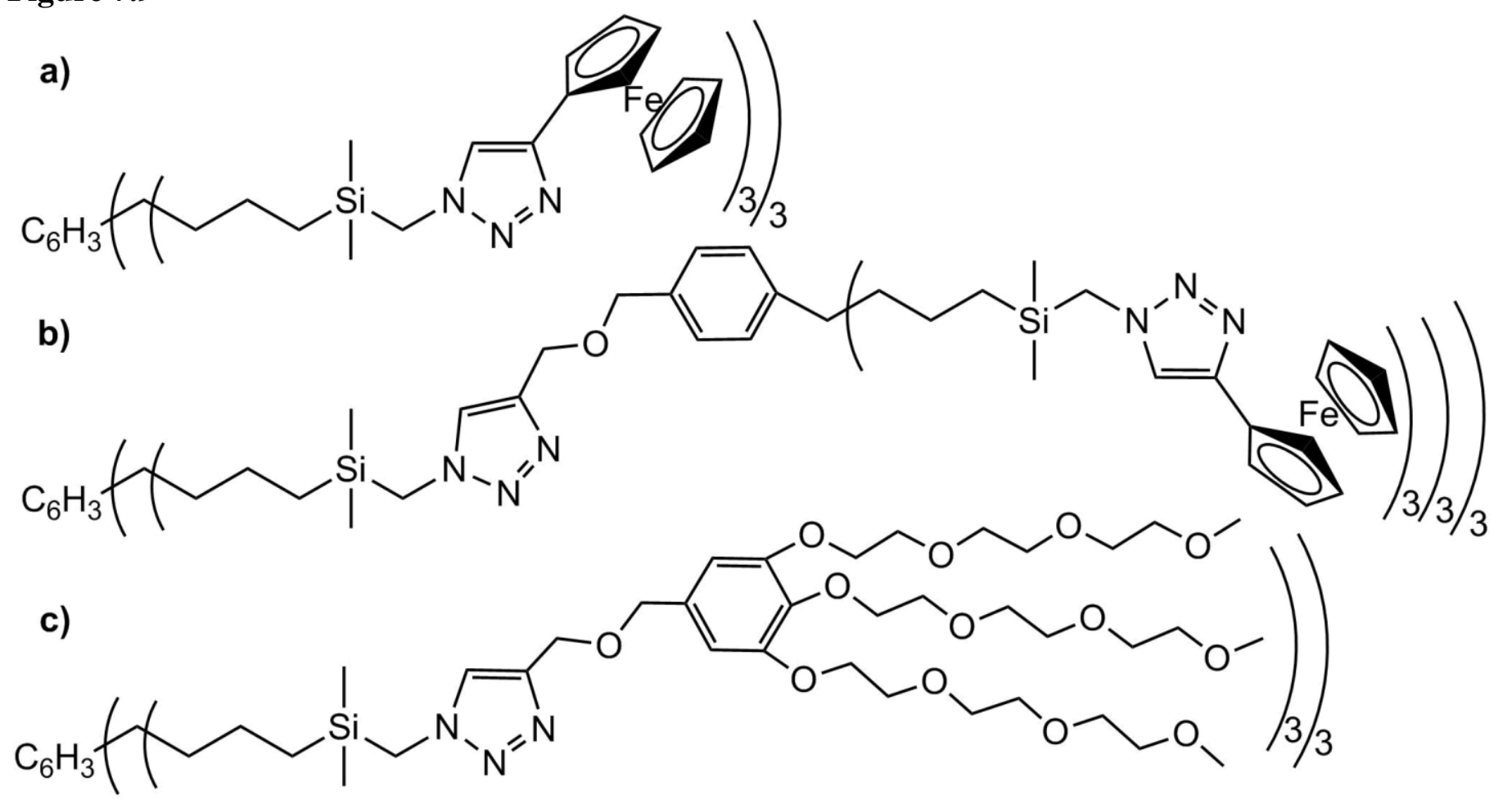




\section{Figure 7.10}

b) 